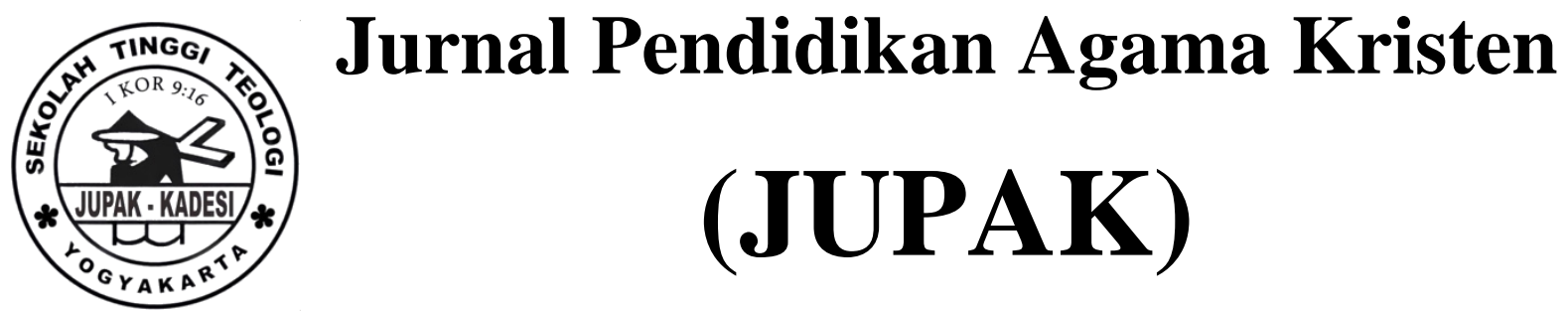

Vol. 2 No. 1 (December 2021) hlm. 36 - 46

Jurnal Pendidikan Agama Kristen (JUPAK)

e-ISSN 2774-3861

https://ejurnal.sttkadesiyogyakarta.ac.id/index.php/jupak

p-ISSN 2774-6399

\title{
https://doi.org/10.52489/jupak.v2i1.38
}

\section{Peran Guru Pendidikan Agama Kristen dalam Pembentukan Karakter Siswa Kelas VIII SMP N 1 Atap Basmuti di Masa Pandemi Covid 19.}

\section{Amran Maher Dionizius Isu ${ }^{2)}$, Maglon Ferdinand Banamtuan ${ }^{3)}$, Yakup Lopo ${ }^{4}$ \\ Sekolah Menengah Pertama Negeri Satu Atap Basmuti, Machonope@gmail.com}

\section{Recommended Citation}

Turabian $8^{\text {th }}$ edition (full note)

Amran Maher Dionizius Isu et al., "Peran Guru Pendidikan Agama Kristen dalam Pembentukan Karakter Siswa Kelas VIII SMP N 1 Atap Basmuti di Masa Pandemi Covid 19.” Jurnal Pendidikan Agama Kristen (JUPAK) 2, no 1 (December 03, 2021): 1, accessed December 8, 2021, https://ejurnal.sttkadesiyogyakarta.ac.id/index.php/jupak/article/view/38.

American Psychological Association $7^{\text {th }}$ edition (Isu, 2021, p.1).

Received: 17 August 2021 Accepted: 4 October 2021 Published: 03 December 2021

This Article is brought to you for free and open access by Sekolah Tinggi Teologi Kadesi Yogyakarta. It has been accepted for inclusion in Christian Perspectives in Education by an authorized editor of Jurnal Pendidikan Agama Kristen (JUPAK).

For more information, please contact juniorichson1995@gmail.com 


\begin{abstract}
The aim of this study is to describe the role of Christian religious education teachers in shaping the character of students at the Basmuti One Roof Junior High School during the covid 19 pandemic. This research is a qualitative research with a descriptive method. The subject of this research is the teacher of Christian religious education subject at Basmuti One Roof State Junior High School. This research can use three steps in data collection, namely: observation, structured interviews and documentation studies. So the results obtained from this study are the teacher's role in shaping the character of students at the Basmuti One Roof Junior High School, namely: 1). The teacher's role in the formation of student character, includes providing motivation, can facilitate, for example in setting an example and increasing student creativity. 2). Characters that are instilled in students are honesty, responsibility, increase student creativity, and cooperation.
\end{abstract}

Keywords: Teachers, Characters, Students, Covid 19 Pandemic.

\begin{abstract}
Abstrak
Tujuan yang ingin dicapai pada penelitian ini adalah untuk mendeskrisikan peran guru pendidikan agama kristen dalam membentuk karakter siswa pada Sekolah Menengah Pertama Negeri Satu Atap Basmuti di masa pandemi covid 19. Penelitian ini merupakan penelitian kualitatif dengan metode deskriptif. Subjek yang menjadi sasaran penelitian ini adalah guru mata pelajaran pendidikan agama kristen Sekolah Menengah Pertama Negeri Satu Atap Basmuti. Pada penelitian ini dapat menggunakan tiga langkah dalam pengumpulan data yakni: observasi, wawancara terstruktur serta studi dokumentasi. Maka hasil yang diperoleh dari penelitian ini adalah peran guru dalam pembentukan karakter siswa di Sekolah Menengah Pertama Negeri Satu Atap Basmuti, yakni: 1). Peran guru dalam pembentukan karakter siswa, meliputi pemberian motivasi, dapat memfasilitasi, sebagai contoh dalam memberikan teladan serta meningkatkan kreatifitas siswa. 2). Karakter yang ditanamkan dalam diri siswa adalah kejujuran, tanggungjawab, tingkatkan kreatifitas siswa, serta kerja sama.
\end{abstract}

Kata-kata kunci: Guru, Karakter, Siswa, pandemi covid 19.

\title{
PENDAHULUAN
}

Pendidikan merupakan proses mendidik, membina, mengendalikan, mengawasi, mempengaruhi, dan mentransmisikan ilmu pengetahuan kepada peserta didik, yang dilaksanakan oleh para pendidik yang merupakan tugas dan tanggung jawab untuk dilaksanakan kepada peserta didik. Secara etimologis (kebahasaan) kata pendidikan berasal dari kata dasar didik yang berarti membantu anak untuk menguasai aneka pengetahuan, keterampilan, sikap, dan nilai yang diwariskan dari keluarga dan masyarakat (Rohman, 2008, p. 5). Menurut Siswinarti (2019, p. 3) pendidikan adalah tulang punggung dari kemajuan suatu bangsa. Tanpa pendidikan yang baik dan benar, maka akan sulit bagi suatu negara untuk maju dan berkembang. Pendidikan juga merupakan proses pewarisan budaya dan karakter bangsa bagi generasi muda dan juga proses pengembangan budaya karakter bangsa 
untuk meningkatkan kualitas kehidupan masyarakat dan bangsa di masa mendatang. Wahyuni \& Rejeki (2014, p. 5) berpendapat bahwa era globalisasi saat ini merupakan suatu tantangan yang telah mengubah berbagai aspek kehidupan masyarakat. Fenomena sosial seperti penyimpangan-penyimpangan yang dilakukan oleh generasi muda telah mengakibatkan kondisi moral banyak yang menjadi rusak.

Menurut Situmorang (2019, p. 103-112) guru pendidikan agama kristen memiliki tugas besar dan sangat kompleks serta terpadu. Sebagai wujud nyata peranan guru pendidikan agama kristen maka harus melaksanakan tugasnya dengan baik dan bertanggungjawab dalam mencapai tujuan pembelajaran yang sempurna. Guru Pendidikan Agama Kristen tidak hanya sekedar mengajar, melainkan memberikan kontribusi yang sangat berharga dan lebih dari sekedar mengajar, yakni berusaha membentuk karakter siswa.

Selanjutnya, Wattimena (2020, p. 30) berpendapat bahwa guru pendidikan agama kristen telah memberikan dirinya untuk melaksanakan tugas pelayanan dan tanggung jawab yang diberikan oleh Tuhan, sekolah dan orang tua dengan baik, mengingat pendidikan agama Kristen bertujuan untuk membuat siswa memiliki karakter yang baik seperti karakter Kristus. Guru pendidikan agama Kristen juga telah menjadi role model dan sahabat yang baik bagi siswa. Sikap, tutur kata dan karakter guru pendidikan agama kristen telah mencerminkan karakter Kristus di dalam proses belajar mengajar di sekolah.

Berdasarkan konsep dari berbagai pandangan tersebut, maka dapat dikatakan bahwa guru mata pelajaran pendidikan agama Kristen harus menjadi fasilitator dalam mengembangan karakter siswa, karena pendidikan agama Kristen merupakan salah satu mata pelajaran yang mengajarkan nilai-nilai ketuhanan serta nilai-nilai kemanusiaan dalam mengamalkan kehidupan yang dapat membuat terbentuknya karakter. Oleh sebab itu, guru mata pelajaran pendidikan agama Kristen harus dapat menanamkan nilai-nilai karakter yang baik bagi siswanya.

Lembaga pendidikan atau sekolah, guru serta orang tua menjadi "motor" penggerak dalam pembentukan karakter siswa. Sebab dalam pembentukan karakter perlu ada kerjasama antar stakeholder pendidikan, karena awal mula munculnya gagasan dalam menerapkan pendidikan karakter di sekolah disebabkan oleh lemahnya peran orang tua, lembaga pendidikan, serta guru dalam membimbing dan mendidik anak.

Siswa Sekolah Menengah Pertama Negeri Satu Atap Basmuti sampai saat ini masih ada yang memiliki karakter yang kurang baik, yaitu adanya siswa yang tidak jujur, siswa yang sering bolos, ada siswa yang kurang disiplin, ada tauran di sekolah, dan sering 
melanggar tata tertib sekolah lainnya. Masalah-masalah tersebut tidak hanya terjadi pada saat jam mata pelajaran pendidikan agama Kristen, tetapi berlaku untuk semua mata pelajaran lainnya.

Kondisi ini sangatlah memprihatinkan karena penghargaan dan penghormatan siswa kepada gurunya masih sangat kurang. Situasi yang seharusnya nyata ialah siswa dapat menghargai guru atau orang yang lebih dewasa dari mereka. Penyebab dari kurangnya penghargaan dan penghormatan siswa kepada guru antara lain kurangnya pembentukan karakter siswa.

\section{METODE}

Azwar (1998, p. 7) mengatakan bahwa penelitian lapangan (Field research) dilakukan dengan tujuan memperoleh data-data yang diperlukan dari kancah atau obyek penelitian yang sebenarnya, dan untuk mempelajari secara intensif latar belakang, status terakhir dan interaksi yang terjadi pada suatu satuan sosial seperti individu, kelompok, lembaga atau komunitas. Sedangkan menurut Sugiyono (2012, p. 1), Penelitian kualitatif adalah metode penelitian yang digunakan untuk meneliti pada kondisi obyek yang alamiah, dimana peneliti adalah sebagai instrument kunci, teknik pengumpulan data dilakukan secara trianggulasi (gabungan), analisis data bersifat induktif, dan hasil penelitian kualitatif lebih menekankan makna dari pada generalisasi. Selanjutnya Sukardi (2009, p. 157) mengatakan bahwa teknik penyajian data penelitian ini dapat menggunakan pola deskriptif. Pola deskriptif adalah metode penelitian yang berusaha menggambarkan dan menginterprestasi objek sesuai dengan apa adanya.

Penelitian ini untuk memperoleh data-data atau peristiwa yang terjadi khususnya peranan Guru dalam pembentukan karakter siswa-siswi di Sekolah Menengah Pertama Negeri Satu Atap Basmuti. Subjek dalam penelitian ini adalah 7 Orang yaitu 2 Guru Pendidikan Agama Kristen dan 5 orang siswa. Teknik pengumpulan data dalam penelitian ini: 1). Observasi; 2). Wawancara; dan 3). Studi Dokumentasi. Langkah-langkah yang dikemukakan oleh Miles \& Huberman (2009, p. 16-18) yaitu: 1). Reduksi data; 2). Display (penyajian data); dan 3). Verification (penyimpulan data). Sasaran yang akan dicapai dalam penelitian ini untuk mengetahui peranan guru dalam membentuk karakter siswa di Sekolah Menengah Pertama Negeri Satu Atap Basmuti. 


\section{PEMBAHASAN}

\section{Peran Guru Sebagai Penasehat}

Salah satu peran guru sekolah pendidikan agama Kristen adalah sebagai penasehat bagi siswa dan orang tua. Meskipun tidak mempunyai keahlian khusus dalam menasehati orang lain, guru pendidikan agama Kristen di Sekolah Menengah Pertama Negeri Satu Atap Basmuti berusaha untuk menjadi sosok yang cakap dalam memberikan nasehat bagi siswanya guna menanamkan nilai-nilai moral dan nilai-nilai kristiani demi pengembangan karakter yang baik pada diri setiap siswa. Menurut Ahmad (1998, p. 69), seorang guru berarti menjadi penasehat dan menjadi orang kepercayaan. Kegiatan pembelajaran juga berada pada posisi tersebut. Siswa akan menemukan gurunya dengan kemauannya sendiri, bahkan mungkin akan menyalahkan apa yang menurutnya salah, serta akan mengadu kepada guru sebagai orang kepercayaannya. Semakin efektif guru menangani setiap permasalahan, semakin efektif juga guru dalam menangani setiap permasalahan, dan semakin banyak kemungkinan peserta didik berpaling kepadanya untuk mendapatkan nasihat dan kepercayaan diri.

Berangkat dari konsep tersebut, fakta Sekolah Menengah Pertama Negeri Satu Atap Basmuti hampir mirip dengan fakta-fakta tersebut, guru Pendidikan Agama Kristen berperan sebagai penasehat bagi peserta dan juga sebagai orang tua bagi peserta didik meskinpun guru tidak memiliki latihan khusus sebagai penasehat. Maka dalam beberapa hal tidak pernah berharap untuk menasehati orang. Maka dapat disimpulkan bahwa guru pendidikan agama Kristen merupakan salah satu figur penting dalam diri siswa yakni menolong dan membantu serta mampu menjadi penasehat yang baik untuk semua siswa.

\section{Peran Guru Sebagai Teladan}

Guru merupakan model atau teladan bagi siswa. Menjadi model atau teladan bagi orang lain tidaklah mudah, tetapi guru harus berusaha menampilkan yang terbaik bagi siswanya, agar setiap siswa dapat mencontoh apa yang dilakukan oleh gurunya (Ahmad, 1998, p. 69). Fakta yang ditemukan di lokasi penelitian saat mewawancarai informan yakni: guru pendidikan agama Kristen akan selalu diperhatikan dan menjadi sorotan peserta didik serta orang di sekitar lingkungannya yang menggangap atau mengakui dia sebagai guru. Guru pendidikan agama Kristen dapat menambahkan aspek tingkah laku lain tentang setiap tindakannya yang muncul di aktivitas kehidupan bersama siswa. Maka dapat disimpulkan bahwa keteladanan guru merupakan hal yang sangat serius di dalam dunia pendidikan bahkan ketika guru berada di dalam kelas. Keteladanan guru juga dapat menjadi dasar dari perubahan sikap siswa. 


\section{Peran guru sebagai pendorong kreativitas siswa}

Salah satu peran guru pendidikan agama Kristen adalah mendorong kreativitas siswanya demi menghasilkan sesuatu. Oleh sebab itu, guru pendidikan agama Kristen dituntut untuk mampu menjadi aktor maupun motivator bagi siswa. Menurut Ahmad (1998, p. 70) guru harus dapat menyadari bahwa kreativitas merupakan yang universal dan oleh kesadaran itu ia harus menjadi seorang kreator dan motivator yang berada di pusat pendidikan. Fakta yang ditemukan guru pendidikan agama Kristen adalah usaha untuk mengembangkan kretivitas siswa melalui berbagai kegiatan yang bernuansa kerohanian, pelestarian lingkungan dan pengembangan budaya di sekolah. Berdasarkan konsep dan kenyataan ini, maka dapat disimpulkan bahwa Kreatifitas guru pendidikan agama Kristen merupakan bentuk dari tindakan yang perlu diperhatikan oleh guru itu sendiri demi mencapai pola yang baik dalam konsep penerapan proses pembelajaran yang baik bahkan dengan inovatif yang baru sehingga siswa memiliki nilai kualitas yang baik.

\section{Karakter Siswa}

\section{Hati Nurani}

Hati nurani merupakan bentuk dari suatu pencapaian keputusan dalam hal perasaan puas atau tidak. Hati nurani hanya ada bagi mereka yang memahami tentang karakter dan asas pemahaman kedewasaan. Siswa-siswa di Sekolah Menengah Pertama Negeri Satu Atap Basmuti sudah mulai terbentuk karakternya dalam nuansa Kristen. Guru pendidikan agama Kristen sudah menanamkan nilai-nilai kristiani kepada semua siswa. Namun, masih ada siswa yang masih melalukan hal-hal yang tidak sesuai dengan hati nuraninya tetapi guru pendidikan agama Kristen langsung mengambil sikap untuk menegur dan menasehatinya supaya jangan diulangi.

\section{Harga Diri}

Harga diri sebagai sesuatu kepercayaan diri seseorang yang berpatokan kepada sesuatu yang terbaik bagi diri sendiri dan bagaimana melakukannya (Coetzee, 2005, p. 10). Fakta siswa-siswi di Sekolah Menengah Pertama Basmuti sudah mulai mampu menguasai diri mereka sendiri dengan tindakan-tindakan dari hati nurani sendiri, bukan dari dorongan orang lain. Hal ini sangatlah membantu guru dalam mengembangkan karakter siswa. Guru harus berperan aktif saat melihat peluang-peluang yang demikian supaya setiap siswa dapat terbentuk dengan karakter-karakter yang baik semasa hidupnya. 


\section{Kerendahan Hati}

Kerendahan hati merupakan sikap dari seseorang yang telah disakiti untuk tidak melakukan pembalasan. Sikap tidak adanya keinginan menjauh sebaiknya harus ada keinginan untuk berdamai dan berbuat baik terhadap pelaku yang sering menyakiti (Mccullough, 2003, p. 540-557). Fakta yang terjadi pada siswa-siswa di Sekolah Menengah Pertama Negeri Satu Atap Basmuti masih ada yang melakukan tindakan kejahatan, tetapi guru pendidikan agama Kristen selalu menasehati. Bahkan, siswa yang menjadi sasaran dari kejahatan pun akan cepat didampingi supaya rasa trauma atau dampak buruk pada kejiwaannya dapat diselesaikan dengan baik. Siswa Sekolah Negeri Satu Atap Basmuti selama ini menggap guru pendidikan agama Kristen sebagai orang tua yang dapat menasehati serta memberikan bimbingan yang baik supaya tidak mengulangi tindakan tersebut. Kerendahan hati merupakan bagian yang sangat penting untuk dimiliki oleh semua siswa. Keredahan hati adalah sikap netral atau sikap yang memiliki nilai rasa yang mampu mengubah amarah menjadi suatu konsep perdamaian yang hakiki.

\section{Cinta Kasih}

Cinta kasih menjadi dasar yang penting dalam setiap perjalanan kehidupan. Guru sebagai Orang tua di sekolah harus mengajarkan serta mempraktekkan nilai cinta kasih kepada anak didik oleh karena anak merupakan titipan Tuhan yang harus memperoleh kasih sayang dari orang tua. Perumpamaan tentang anak yang terhilang dalam Lukas 15:11-32, mengajarkan kepada semua guru agar memiliki kasih yang tulus dalam melayani anak-anak yang dipercayakan Tuhan. Menurut Erich (1983, p. 24-27) cinta kasih mengandung unsur dasar tertentu yaitu pengasuhan seperti cinta orang tua kepada anaknya, tanggung jawab dan perhatian.

\section{Saling Menghormati}

Siswa-siswi Sekolah Menengah Pertama Negeri Satu Atap Basmuti, berasal dari berbagai suku dan agama. Tingkat saling menghormati sangatlah tinggi, karena sifat dan sikap selalu dijaga, sehingga tingkat toleransi kerukuan selalu ditunjukan kepada siapapun dalam bentuk perbedaan yang ada di lingkungan sekolah bahkan di lingkungan sekitarnya. Sikap saling menghormati menjadi penting untuk dimiliki oleh semua siswa supaya dalam berinteraksi antara siswa dengan siswa, dan siswa dengan guru dapat menciptakan keharmonisan dalam segala aktivitas yang dilakukan. 


\section{Berdoa Bersama}

Di Sekolah Menengah Pertama Negeri Satu Atap Basmuti terdapat jadwal yang dibuat oleh guru pendidikan agama Kristen yang menyatakan bahwa setiap hari Jumat ada kegiatan doa bersama. Kegiatan ini diwajibkan kepada siswa untuk mengikuti kebaktian sekolah minggu. Langkah-langkah yang dibuat di Sekolah Menengah Pertama Negeri Satu Atap Basmuti membentuk siswa untuk memiliki kepribadian yang senang membaca Firman Tuhan serta mengenal lebih dekat kasih Tuhan yang nyata di dalam diri mereka. Maka dengan langkah-langkah ini mereka di latih dalam menggunakan benda-benda rohani dengan tepat seperti sali, patung, dan gambar. Keluarga dan sekolah merupakan fasilitator anak untuk belajar mengetahui dan mengenal siapa Allah, Yesus Putra-Nya yang mengasihi, mengampuni, memelihara dan menjaga semua manusia yang dengan setia menjawab doadoa. Pengetahuan ini tidak hanya berhenti pada teori tetapi harus dilaksanakankan dalam setiap aktivitas kehidupan anak, misalnya: Berdoa mengucap syukur pada waktu makan, bangun pagi, ataupun hendak melakukan aktivitas-aktivitas lainnya.

\section{Kejujuran}

Kejujuran adalah alasan yang sangat penting dalam membentuk karakter siswa. Ketika berbicara kejujuran tidak semua manusia mampu berkata jujur akan pribadinya sendiri dan orang di sekitarnya. Oleh sebab itu kejujuran harus diterapkan dari masa kanak-kanak yaitu masa tahap pertumbuhan. Seperti Amerika Serikat yang sangat memperhatikan perkembangan pribadi peserta didik untuk hidup harmonis dengan harapan terbentuknya pribadi yang jujur (Sahertian et al., 2021, p. 150).

Aktifitas sosial dalam keluarga diharapkan dapat membentuk kepribadian anak yang memiliki sikap jujur, taat, setia dan disiplin. Orang tua harus sering mengajarkan kepada anak akan kejujuran, namun prakteknya masih belum maksimal. Misalnya, secara diam-diam memberikan uang kepada anak tanpa diketahui oleh anggota keluarga yang lain atau mengharuskan anak mengikuti kegiatan gerejawi padahal ia sebagai orang tua jarang mengikutinya. Orang tua harus menjadi teladan yang baik bagi anggota keluarganya. Jujur berarti sesuainya ucapan secara lisan dengan kenyataan hidup atau keselarasan antara berita dan fakta. Dengan demikian kejujuran merupakan salah satu bagian yang sangat penting yang harus diajarkan oleh orang tua kepada anak-anaknya. 


\section{Peran Guru Pendidikan Agama Kristen dalam membentuk Karakter Siswa Sekolah Menengah Pertama Negeri Satu Atap Basmuti}

Peranan guru pendidikan agama Kristen dalam membentuk karakter siswa di Sekolah Menengah Pertama Negeri Satu Atap Basmuti dilakukan dengan ketulusan hati dan kerja yang ekstra. Menyatukan banyak karakter siswa merupakan pekerjaan yang sangatlah berat, maka dibutuhkan banyak pihak untuk bisa membantu. Pihak-pihak yang dimaksudkan adalah orang tua siswa, guru bimbingan konseling, dan guru mata pelajaran lainnya sehingga dapat menyatukan karakter siswa yang dari berbagai suku, buda dan agama di Sekolah Menengah Pertama Negeri Satu Atap Basmuti.

Ada beberapa peranan guru agama Kristen yang telah dibahas sebelumnya, yang menggambarkan bahwa dalam mengembangkan kepribadian siswa untuk takut akan Tuhan, maka guru pendidikan agama Kristen harus dapat melakukan strategi-strategi dalam membentuk karakter siswa. Siswa harus bersedia dan memberikan dirinya untuk mengikuti seluruh rancangan guru dalam menanamkan nilai-nilai moral dan nilai-nilai kristiani.

\section{REKOMENDASI PENGEMBANGAN PENELITIAN}

Penelitian ini berlangsung di Sekolah Menengah Pertama Negeri Satu Atap Basmuti. Dari hasil penelitian peneliti berharap biasa bermanfaat bagi orang-orang tua siswa, guru mata pelajaran, pihak sekolah dan pemerintah. Dari penelitian ini masih ada kekurangan. Oleh sebab itu, penulis sangat mengharapkan kritik maupun saran agar dapat menyempurnakan hasil penelitian ini dan penelitian yang akan datang. Penulis juga berharap kepada peneliti lain agar biasa menggunakan hasil penelitian ini sebagai bahan referensi. Dan juga bagi peneliti lain agar dapat mengembangkan penelitiannya yang sama tetapi dengan melihat aspek lain yang tidak dijangkau oleh penulis.

\section{KESIMPULAN}

Terdapat dua bagian penting yang ditemukan dalam penelitian peran guru pendidikan agama Kristen dalam membentuk karakter siswa di Sekolah Menengah Pertama Negeri Satu Atap Basmuti. Pertama, Peran guru pendidikan agama Kristen di Sekolah Menengah Pertama Negeri Satu Atap Basmuti berusaha dengan kemampuan yang dimiliki untuk melakukan beberapa peranan penting yakni: harus menjadi penasehat, pembimbing, motivator, dan serta mengembangkan kreativitas siswa. Kedua, Siswa-siswi di Sekolah Menengah Pertama Negeri Satu Atap Basmuti selalu menjalankan nilai-nilai kristiani yang selalu diberikan oleh guru pendidikan agama Kristen dalam membentuk karakter siswa seperti: hati nurani, saling menghargai, berdoa bersama, merendahkan diri. 


\section{BIODATA}

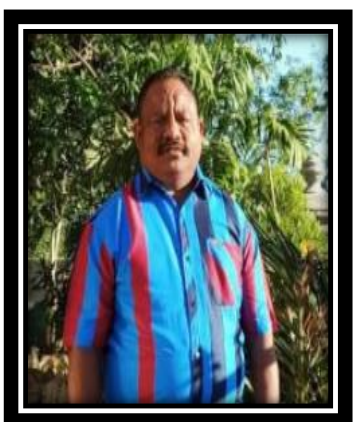

Amran Isu adalah bagian dari keluarga besar Kementerian Agama Kabupaten Timor Tengah Selatan. Dan sebagai Pengawas Mata pelajaran Pendidikan Agama Kristen. Dia banyak menulis tentang pendidikan Kristen yang kental dengan makna-makna Pendidikan Kristen sesuai dengan pengembangan dunia saat ini. Melalui tulisannya, diharapkan kiranya dapat menjadi salah satu pendukung dalam kemajuan ilmu pengetahuan di Indonesia.

\section{Amran Maher Dionizius Isu}

Surel:amranisu21@gmail.com

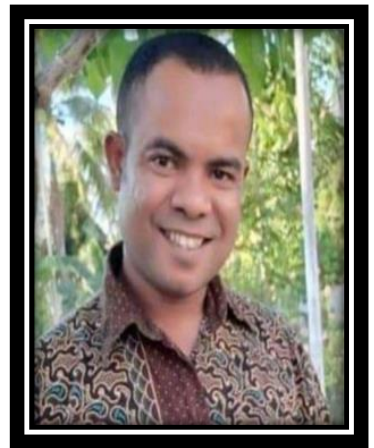

Maglon Ferdinand Banamtuan adalah Dosen Institut Agama Kristen Negeri Kupang. Dia banyak menulis artikel tentang pendidikan agama Kristen, pendidikan di sekolah, serta budaya. Dan sudah dipublikasi di Jurnal Nasional terakreditasi. Melalui tulisannya ia berharap banyak orang yang diberkati dalam hal penambahan pengetahuan atau referensi dalam penelitian dan pengembangan dalam dunia pendidikan.

\section{Maglon Ferdinand Banamtuan}

Surel: machonope@gmail.com

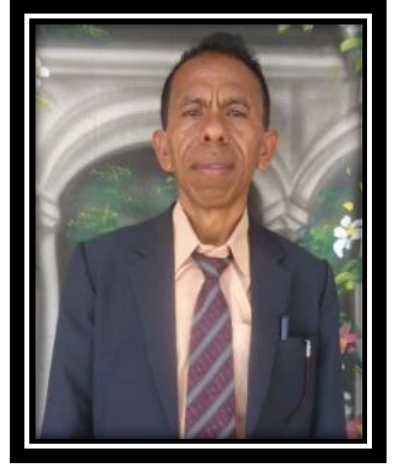

Yakup Lopo adalah guru Mata Pelajaran Pendidikan Agama Kristen di Sekolah Menengah Pertama Satu Atap Basmuti, Kecamatan Kuanfatu Kabupaten Timor Tengah Selatan. Melalui tulisannya ia berharap termotivasi dalam mengelola kelas hingga pengembangan mata pelajaran Pendidikan Agama Kristen di tingkat sekolah menengah pertama.

\section{Yakup Lopo}

Surel: yakuplopo65@gmail.com

\section{DAFTAR PUSTAKA}

Ahmad, Marimba. (1998). Pengantar Filsafat Pendidikan Islam. Bandung: Al-Maearif. Azwar, Saifudin. (1998). Metodologi Penelitian. Yogyakarta: Pustaka Pelajar Offset. 
Amran Maher Dionizius Isu, Maglon Ferdinand Banamtuan, Yakup Lopo.

Coetzee, M. (2005). Employee Commitment. University of Pretoria etd. http://upetd.up.ac.za/thesis/available/etd04132005130646/unrestricted/05chapter5.pdf . 16 Maret 2021.

Erich, Fromm. (2002). Cinta, Seksualitas, Matriaki, Gender. Yogyakarta: Jalasutra.

Gunawan, Imam. (2013). Metode Penelitian Kualitatif. Teori dan Praktik. Jakarta: PT Bumi Aksara.

McCullough, M. E; Fincham, F. D.\& Tsang,J. (2003). Forgiveness, forbearance, and time: The temporal unfolding of transgression-related interpersonal motivations. Journal of Personality and Social Psychology.

Miles,B. Mathew dan Huberman, Michael. (1992). Analisis Data Kualitatif Buku Sumber Tentang Metode-metode Baru. Jakarta: UIP.

Mulyasa, E. (2009). Menjadi Guru Profesional. Bandung: PT Remaja Rosdakarya.

Rohman, Arif, (2008). Memahami pendidikan dan ilmu pengetahuan. Yogyakarta: Laksbang mediatama.

Sahertian, N. L., Ming, D., Istinatun, H. N., \& Sirait, J. R. (2021). Penerapan Model Pembelajaran Jerold E KEM Di Smp Hanuru. Jurnal Pendidikan Agama Kristen (JUPAK), 2(1), 143-165. https://doi.org/10.52489/jupak.v2i1.26

Siswinarti, Putu Ratih. (2019). Pentingnya Pendidikan Karakter Untuk Membangun Bangsa Beradab, (diunduh dari https://www.researchgate.net/directory/publications tanggal 18 Maret 2019 pada 18.02 WIB).

Situmorang, Kasminton; Lahagu, Ardianto; Purba, Benteng Martua Mahuraja. (2019). "Peran Guru Pendidikan Agama KristenDalam membentuk Karakter Siswa" Real Didache: Jurnal Pendidikan agama Kristen, Vol 4, No 2 September 2019.

Sugiyono. (2012). Memahami Penelitian Kualitatif. Bandung: Alfabeta.

Sukardi. (2009). Metodologi Penelitian Pendidikan: Kompetensi dan Praktiknya. Jakarta: PT Bumi Aksara.

Wahyuni, Naning Dwi dan Rejeki, Sri. (2014). Pola Pendidikan Karakter Usia Dini Di TK Pertiwi XVI Kecamatan Pundong Kabupaten Bantul T.P. 2013/2014. Bahan Ceramah pada hari Rabu, 13 Agustus 2014.

Wattimena, Shyllia Dea. (2020). Peran Guru Pendidikan Agama Kristen dalam Pendidikan Karakter Siswa di SMP Kristen GPIB Balikpapan. Skripsi Fakultas Teologi Universitas Kristen Satya Wacana Salatiga. 